\title{
İexiscope.
}

EXCERPTS WILL BE FURNISHED AS FOLI,OWS :

From the Hollandish, Swedish, From the French,-German and Danish, Norwegian, German, Portuguese, Roumanian, Spanish and Itatian:

F. H. PRITCHARD, M.D., Norwalk, $\mathrm{O}$.

From the Swedish, Danish, Norwegian and Finnish:

Frederick PETERSON, M.D., New York.

From the German :

WILIIAM M. LESZYNSKY, M.D., New York.

Belle MacdonaLd, M.D., N. Y.

From the French:

L. Fiske Bryson, M.D., N. Y.

G. M. Hammond, M.D., N. Y.

Itatian:

JoHN W. BranNaN, M.D., N. Y.

From the Italian and Spanish:

Wiritiam C. Krauss, M.D., Buffalo, N. Y.

From the Italian and French:

E. P. HuRD, M.D., Newburyport, Mass.

From the German, Italian, French and Russian:

AI.BERT PICK, M.D., Boston, Mass.

From the English and American: A. FREEMAN, M.D., New York. From the French and Gernan:

W. F. RobInson, M.D., Albany.

The Editor will not accept as ORIGINAL, ARTICLES and CliNICAI. CASES those that have appeared elsewhere.

Authors are requested to make none but typographical corrections ou the proof seut to them. The manuscript must represent the final form in which the article is to be printed.

PATHOLOGICAL.

\section{BILATERAL PARALYSIS OF THE EXTERNAL RECTI.}

In the "Progrès Médical," 1891, No. 36, Dufour reports three cases of commencing tabes with the unusual symptom of isolated bilateral abducens paralysis.

I.-Male, fifty years of age. Diplopia had existed for some time. Paralysis of both externi, contracted pupils, feeble reaction to light. Knee-jerks present. Romberg's symptom. No evidence of syphilis.

II.-Female, fifty-four years of age. Twelve years ago attack of paralysis of third nerve (left). One year later transient paresis of both externi. Two years ago paralysis of left abducens; soon after the right was also affected. Absence of light-reflex. Headache and pain 
in intercostal and bulbar region. Knee-jerks present. No evidence of syphilis.

III.-Male, thirty-eight years of age, without signs of syphilis. Two years ago transient diplopia, which has now become permanent. Bilateral abducens paralysis. Loss of knee-jerks. Weakness in legs. Romberg's symptom.

The author assumes the presence of a nuclear lesion in all of the cases, and emphasizes the diagnostic and prognostic value of similar observations. (Neurolog. Centralblatt, I 892 , No. 2.)

W. M. L.

\section{FURTHER STUDIES ON SYPHILIS OF THE CENTRAL NERVOUS SYSTEM.}

The "Centralblatt $f$. Nervenheilkunde und Psychiatrie" contains a communication by Moeli and Marinesco which presents some additional facts in regard to these cases. The report was worked up from four cases, the first of which presented as the only symptom, complete paralysis of the motor oculi. The pathological conditions found at post-mortem examination consisted of a tumor in the posterior cerebral region, simple infiltration, and degeneration of the nerve trunks with adhesions of the meninges. Another case was one of gumma of the pons, with alterations in the vessels of the cord. There were no characteristic symptoms during the life of the patient, pointing to tumor. A third case was gumma of the posterior column, with distinct diminution in the gray matter of the central spinal canal. Considerable atrophy could be seen in the region of the nuclei of the hypoglossus, the median part of the crus, and in Broca's centre. The nerve trunks were normal. Clinically the disease had not presented a single indication of paralysis, but symptoms pointing to polyneuritis. The fourth case showed a small spot of softening in the pons. There was some degeneration in the nerve fibres of the olivary body and of the arcuatæ interna. The authors submit the following rísume of the microscopical findings in these cases. In the syphilitic cases, the alterations found in the vessels were of an inflammatory character, and indicated degenerative changes consisting of hyaline thickening of the vessel wall with, in some instances, an almost entire obliteration of their lumen. The alteration in the nerve tissues seemed to be brought about by the disturbance of circulation due to the changes in the 